\title{
Leaks detection in sequence of environmental infrared images
}

\author{
by B. Bukowska-Belniak*, A. Leśniak*
}

\begin{abstract}
* AGH University of Science and Technology, al. Mickiewicza 30, 30-059 Krakow, Poland, bukowska@agh.edu.pl, lesniak@agh.edu.pl
\end{abstract}

\begin{abstract}
This work presents the method of leaks detection in sequence of infrared images. Infrared field measurements were taken on small experimental embankment during flood process. The leak processes that took place in the embankment are observed during experiment in infrared images. Image processing method allowed to localize the leak in the thermal images, despite the impact of external factors that disturb the measurements and differences in objects emissivity in the observed scene.
\end{abstract}

\section{Introduction}

Infrared thermography is a fast and remote method used to measure temperature based on infrared radiation registered on the detector array [1]. Infrared cameras use different types of detector arrays. One of them is microbolometer focal plane array. Infrared cameras based on this type of uncooled detectors are cheaper than cooled photon detectors. The disadvantage of cooled detector is the thermal drift [2]. Infrared measurements are exposed to high impact of external conditions, disturbances and ambiguities in the interpretation [3].

The infrared images were registered during field measurements taken on small experimental embankment subjected a flooding process $[4,5]$. This embankment is located in open terrain, under a tent, which protect it from rain. Infrared measurements showed that the tent is transmitting infrared radiation from the Sun. The thermal images were captured by FLIR T620 infrared camera with microbolometer focal plane array, which spatial resolution is $620 \times 480$ pixels. Used lens did not allow to register the view on the whole embankment's water side surface. Applying NUC procedure every 1 minutes allowed to minimize thermal drift.

\section{Sequence of infrared images processing method}

Images were recorded in every 30 seconds. The images were registered sequentially: left side of embankment, center, right side, center, left side and so on. For the analysis the images of central part of the embankment were used. They were taken every minute. First stage of processing was to reject blurred images and these one in which a man is in the field of view. Next processing steps were performed using MATLAB software [6]. Because the images do not cover exactly the same scene, at the beginning the crop of the region of interest using automatic cropping procedure was done(figure 1).

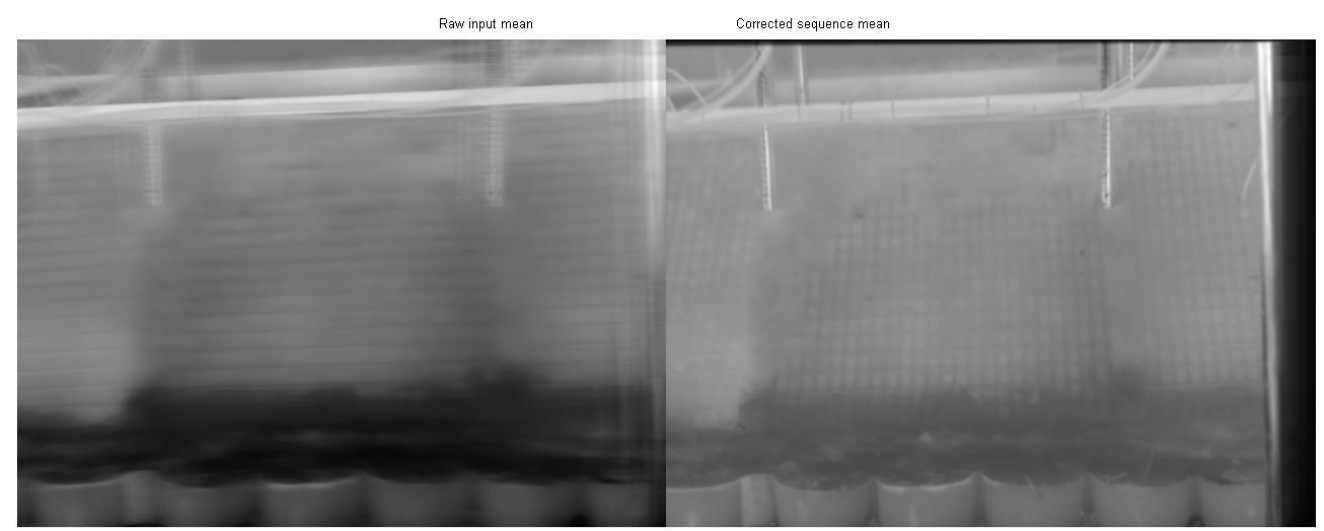

Fig. 1. Mean of infrared images before (left image) and after (right image) cropping procedure.

In analyzed sequence of images we can see very strong influence of solar radiation, especially in the moments when the Sun is not behind the clouds. This caused flickering during playing the sequence. The next step was to bring 


\subsection{1/qirt.2016.016}

images to the same level of greyness. This procedure was performed using the registered temperatures obtained on the cross section in the middle part of the area that was not exposed to the influence of other factors (figure 2).

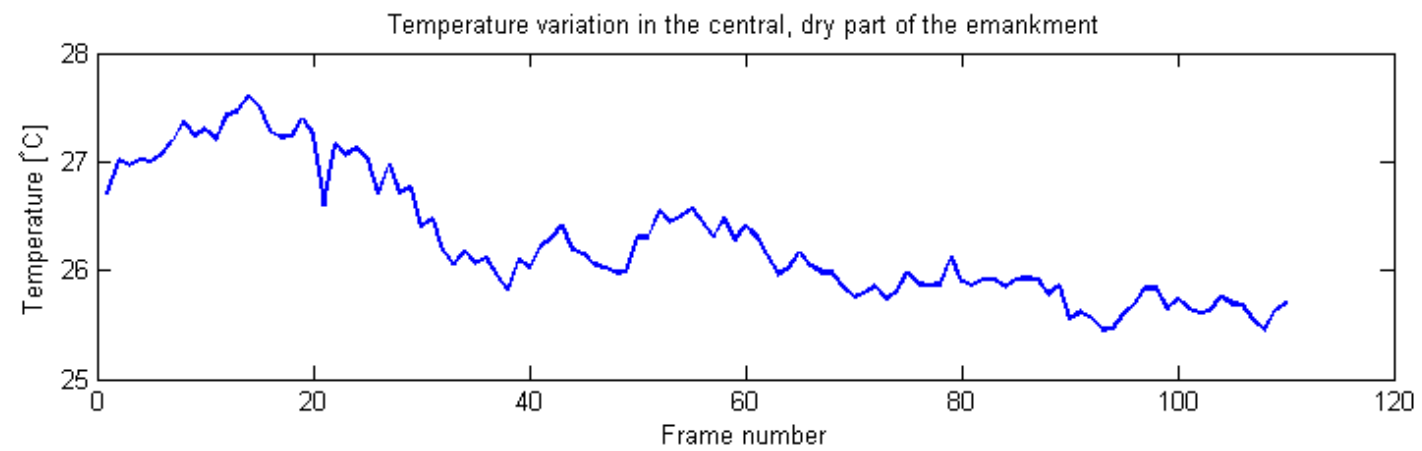

Fig. 2. Mean of temperature variation in the central part of the images.

Next, the several image processing procedures, based on different operations on images were performed. Most important of them are: multiplication, subtraction, thresholding, morphological operations [7]. These procedures made it possible to isolate leak area on thermal image (figure 3).

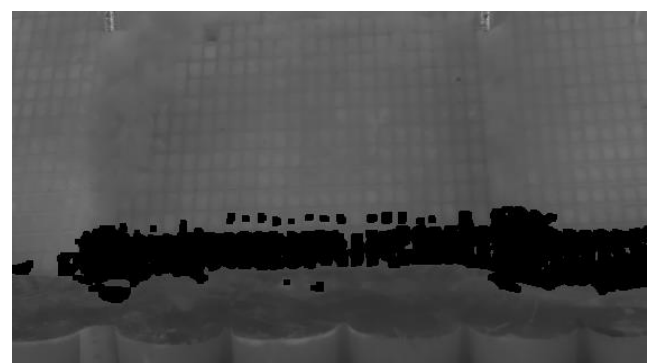

Fig. 3. Example of leakage detection result.

\section{Conclusions}

Infrared thermography allowed to register the leak of water in experimental embankment. Image processing methods allowed to localize the leak on the thermal images, despite the impact of external factors on the measurement and differences in objects emissivity in the observed scene.

This work was supported by the National Centre of Research and Development (NCBiR), Poland, project PBS1/B9/18/2013 (no. 180535) [1].

This work was partly supported by the AGH University of Science and Technology, Faculty of Geology, Geophysics and Environmental Protection, as part of statutory project no. 11.11.140.613.

\section{REFERENCES}

[1] Więcek B., De Mey G.: „Termowizja w podczerwieni. Podstawy i zastosowania.” Wydawnictwo PAK, Warszawa, 2011.

[2] Olbrycht R., Więcek B., "New approach to thermal drift correction in microbolometer thermal cameras", Quantitative InfraRed Thermography Journal, 12:2, 184-195, 2015.

[3] Minkina W., Dudzik S.: "Infrared thermography: Errors and uncertainties", Blackwell Science, 2009.

[4] ISMOP - Computer System for Monitoring River Embankments (in Polish: Informatyczny System Monitorowania Obwałowań Przeciwpowodziowych), www.ismop.edu.pl.

[5] Bukowska-Belniak B., Leśniak A., Kessler D., "Thermographical monitoring of leak processes in embankments", AITA $2015,13^{\text {th }}$ international workshop on Advanced Infrared Technology \& Applications: proceedings, pp. 7678, 2015.

[6] MathWorks help documentation http://www.mathworks.com

[7] Lim J. S.: Two-dimensional signal and image processing. Englewood Cliffs, NJ, Prentice Hall, 1990. 